\title{
TINGKAT PENGETAHUAN KESELAMATAN PENGUNJUNG ARUNG JERAM DI WISATA SUNGAI CISADANE BOGOR, JAWA BARAT.
}

\author{
Faris Bachtiar \\ Marlinda Budiningsih Dan Abdul Kholik
}

\begin{abstract}
ABSTRAK. Pengetahuan keselamatan penting bagi para pengunjung arung jeram karena dalam aktifitas ini rentan akan cedera dan kecelakaan. Penelitian deskriptif ini bertujuan untuk mengetahui tingkat pengetahuan keselamatan pengunjung. Sampel yang digunakan pada penelitian ini yaitu sejumlah 60 pengunjung pada tanggal 1 November sampai dengan 1 Januari 2017. Angket yang terdiri dari 4 dimensi yaitu kenyamanan diri, kenyamanan fisik, kenyamanan psikologi dan kenyamanan pengalaman yang berjumlah 20 soal yang disebar kepengunjung arung jeram wisata sungai Cisadane.

Hasil penelitian menunjukkan tingkat pengetahuan keselamatan pengunjung arung jeram sungai Cisadane, Bogor, Jawa Barat adalah sedang, dengan nilai setiap dimensi hampir menyentuh $60 \%$. Range valliditas memiliki nilai $\left(\mathrm{r}_{\text {hitung }}=0.08\right)$ dan nilai reabilitas sebesar 0,73 .

Kesimpulan akhir yang dapat diperoleh melalui penelitian ini adalah tingkat pengetahuan keselamatan pengunjung arung jeram di wisata sungai Cisadane, Bogor, Jawa Barat adalah sedang.
\end{abstract}

\section{Kata Kunci : Pengetahuan, Keselamatan, Arum Jeram}

\section{PENDAHULUAN}

Era globalisasi ini masyarakat umum sibuk akan dengan pekerjaannya dan mementingkan akan kesibukannya, disamping itu semakin masyarakat banyak bekerja akan menimbulkan efek stress dan depresi yang tinggi, kemudian akan menyebabkan suatu gejala yang mengakibatkan terjadinya gangguan kesehatan pada tubuhnya. Pada umumnya suatu individu membutuhkan suatu hiburan yang bisa membuat seseorang senang dan bisa menghilangkan stress, liburan itu bisa menghilangkan kejenuhan pekerjaan seseorang.

Masyarakat di era zaman sekarang bekerja pada jam kerja di hari senin sampai jumat, pada hari sabtu dan minggu digunakan untuk berlibur, khususnya masyarakat dikawasan jabodetabek yang memanfaatkan hari sabtu dan minggu untuk berkegiatan rekreasi, seperti mengunjungi kebun binatang, mengunjungi museum dan lain sebagainya. Adapun liburan yang biasa diambil masyarakat jabodetabek yaitu liburan dengan berkegiatan olahraga ekstrem contohnya hiking, rafting, diving, caving, climbing wall dan sebagainya.

Olahraga Ekstrem merupakan olahraga yang sangat menantang akan keberanian, kesiapan fisik dan mental. Olahraga ini juga sangat berguna untuk menambah pengalaman, meningkatan sikap dan perilaku seseorang serta meningkatkan mental terhadap rasa takut.

Olahraga ekstrem yang dimaksud adalah arung jeram, merupakan salah satu olahraga ekstrem yang sudah mendunia, dengan kesungguhan rasa serunya mengarungi sungai yang bisa berdegup kencang hati seseorang atau pelakunya, tak hanya itu para penikmat olahraga arung jeram ini bisa mengambil manfaat tentang rasa menjaga keadaan lingkungan sungai dan bisa berinteraksi dengan bagian bagian dunia air, akan tetapi pada kenyataan saat ini banyak sekali para penikmat olahraga ini yang salah akan pemahaman tentang olahraga ini.

Kenyataannya arung jeram adalah salah satu kegiatan di air, tapi di arung jeram ini harus mementingkan persiapan diri atau pengetahuan akan kegiatan arung jeram ini 
dan juga agar mencegah sesuatu yang tidak diinginkan terjadi di arung jeram. Era masa kini olahraga arung jeram sudah banyak pengunjung yang ingin melakukan arung jeram, tapi dilapangan sering kali dijumpai banyak kecelakaan yang merenggut korban jiwa yang tidak sedikit. Ada banyak faktor yang mengakibatkan sering terjadi kecelakaan di arung jeram contohnya diperalatan yang kurang safety, keadaan sungai yang riam dan liar, keadaan individu atau manusianya yang kurang siap untuk melakukan kegiatan tersebut.

Keselamatan juga meliputi beberapa aspek untuk menunjang kegiatan arung jeram di lapangan nantinya, aspek tersebut antara lain suatu keadaan pembebasan atau rasa aman dalam kondisi sehat fisik, sosial, spritual, mental dan sebagai bertujuan untuk menghindari cidera, dari pengertian diatas ada 4 aspek yang harus dilaksanakan agar tidak adanya kecelakaan yang kecil atau besar.

Pertama di aspek fisik ini merupakan aspek yang sangat penting untuk menunjang kegiatan, fisik ini mengaharuskan berlatih dengan cara berolahraga seperti lari dan masih banyak lagi kemudian aspek sosial yaitu dengan cara menghormati dan bekerja sama ketika disaat melakukan kegiatan arung jeram, lalu di aspek spritual para pelaksana dan penggiat harus melakukan aktiftas berdoa dengan maha penciptanya agar kecelakaan tidak terjadi dan bisa dijadikan sarana keselamatan bagi dirinya sendiri selanjutnya diaspek finansial diaspek ini juga aspek yang sangat penting.

Seorang pengunjung harus mempersiapkan biaya dan materi yang akan nanti dilaksanakan agar pelaksanaanya sesuai dengan niat dan rencana yang sudah direncanakan dan aspek terakhir yaitu aspek mental, diaspek ini seorang pengunjung harus mempunyai rasa keberanian, psikologi, dan mental dalam mengatasi rasa takut agar nanti dilapangan kemampuan mental nya terlatih dengan kondisi lapangan atau sungai yang sangat menantang dan bisa mendebarkan rasa jiwa nya.
Arung jeram adalah salah satu olahraga ekstrem di dunia yang sudah dikenal banyak kalangan dari masyarakat awam, penggiat, penghobi, mapala dan orang orang yang sekedar hiburan, menambah pengalaman dan mengabadikan diri dengan berfoto selfie sepuasnya, olahraga ini juga mempunyai kesempatan memperkaya diri dibidang bisnis dan selain itu arung jeram juga bisa dikatakan olahraga yang beresiko tinggi, seperti halnya yang diberitakan dikota Batu Malang Jawa Timur pada tahun 2014, ada dua sejoli yang mengikuti kegiatan ini dan dua sejoli ini terbawa arus dan dinyatakan hilang karena mengikuti olahraga arung jeram ini padahal dua sejoli minggu pekan akan mengadakan pernikahan.

Peneliti menelusuri tentang banyaknya korban yang berjatuhan di arung jeram, peneliti ingin melakukan penelitian tentang faktor pengetahuan keselamatan para pengunjung yang ingin melakukan arung jeram agar kelak nanti dalam berkegiatan arung jeram bisa meminimalisir adanya korban.

Alasan Peneliti melakukan penelitian ini adalah ingin mengetahui pengunjung tentang keselamatan diri sendiri dalam mengikuti kegiatan pengarungan jeram dimedan yang sesungguhnya dan mengetahui medan-medan sungai dan kondisinya disaat melaksanakan pengarungan bersama teman dan kerabatnya dan tidak hanya itu pengunjung juga bisa mengaplikasikan pengetahuan keselamatan dalam kehidupan sehari-hari dilingkungan kerja, keluarga maupun di suasana darurat terhadap sesuatu yang tidak di inginkan berupa kecelakaan diruang terbuka seperti mengikuti pengarung jeraman yang dilakukan secara bersama-sama dengan sahabat,teman kerja, teman hidup ataupun keluarga. Sehingga kelak untuk menghindari kecelakaan yang berakibat fatal dan berdampak kelangsungan pengunjung yang mengikuti kegiatan arung jeram disungai. 


\section{PENGETAHUAN}

Pengetahuan sesunguhnya berasal dari bahasa Yunani yaitu kata philosophia yang artinya mencintai kebijakan, kemudian dalam bahasa inggris yaitu knowledge dan dalam bahasa Yunani yaitu falsafah yang artinya cinta kearifan. Mempelajari pengetahuan harus memahami arti dari dan pengetahuan, kedua kata ini mempunyai arti yang berbeda sedangkan pengetahuan adalah (knowledge), kemudian pengetahuan dalam bahasa arab ialah, ya'lamu.

Pengetahuan berperan dalam menentukan kehidupan manusia serta perkembangan teknologi, manusia itu untuk melakukan kegiatannya berdasarkan pada pengetahuan yang didapatkan dari sejak lahir dan berfungsi sebagai akal pikiran sehat, kehendak, dan kondisi fisik prima. Hal ini sangat menunjang untuk mengetahui apa yang mendasari dari kajian definisi pengetahuan dan sebagai faktor penentu untuk melakukan kegiatan-kegiatan manusia.

Pengetahuan itu juga mempunyai komponen-komponen, asal dan bisa berperan dalam kehidupan sehari hari manusia. Komponen-komponen yang dapat dijelaskan dan dipahami oleh khalayak yaitu ada 6 macam komponen.

Menurut Bahm dalam Surajiyo komponen pengetahuan melibatkan paling tidak enam macam komponen, yaitu problem, attitude, method, activity, conclution, effects". Banyak sekali para ilmuan yang berpendapat, opini atau mengemukakan tentang pengetahuan, pengetahuan itu sendiri mempunyai rekam jejak dari zaman pra Yunani kuno sampai di zaman kontemporer. Jadi perkembangan pengetahuan itu dinamis bisa menyesuaikan dengan perkembangan zaman, sesuai kebutuhan manusia dan juga penerapannya disetiap zaman.

Definisi pengetahuan, para filsuf mengungkapkan pendapatnya berbeda beda, seperti yang diungkapkan. Sidarta dalam Surajiyo mengatakan pengetahuan adalah yang disistematiskan, pengetahuan juga dapat dirumuskan dengan suatu metode empirik yaitu metode yang terikat pada ruang dan waktu, tak hanya itu pengetahuan pun bersifat rasional, emprikal, sistematikal, umum dan terbuka, akumulatif. Pengetahuan itu mempunyai cabang cabang seperti pengetahuan matematika, pengetahuan alam, dan sebagainya.

Setelah memahami makna pengetahuan itu berasal dari knowledge, yang artinya atau memiliki definisi suatu unsur mengetahui serta mengikuti kesadaran mengenai hal yang diinginkan. Dalam kaitan ini juga berpengaruh pada manusia, manusia tanpa pengetahuan itu seperti objek transparan yang belum mengetahui apapun, pengetahuan juga bisa difungsikan sebagi pembentuk struktur pikiran manusia, yaitu mengamati (observasi), menyelidiki (investigate), percaya (believe), hasrat (desire), dan mengatur (organize) dan maksud (intent)".

Pengetahuan juga memiliki jenis jenis yaitu pengetahuan ilmiah dan pengetahuan non ilmiah, pengertian pengetahuan non ilmiah ialah pengetahuan yang tidak menggunakan ilmiah sedangkan pengertian pengetahuan ilmiah adalah pengetahuan yang menggunakan kaidah-kaidah ilmiah dan sesuai aturan.

Fred N Kerlinger dalam Ahmad Tafsir berpendapat Kerja mencari hubungan sebab akibat atau mencari pengaruh sesuatu terhadap yang lain. Asumsi dasar sains adalah tidak ada kejadian tanpa sebab, dan dirumuskan dalam ungkapan post hoc, ergo propter hoc (ini, tentu disebabkan oleh ini). Asumsi ini benar bila sebab akibat itu memiliki hubungan rasional.

Pengetahuan itu mempunyai suatu kebenaran yaitu teori teori yang dinamis dan mengikuti perkembangan zaman terbukti dengan banyaknya pendapat yang membicarakan makna dari ilmu pengetahuan, di zaman kontemporer sekarang pengetahuan itu bisa dihubungkan oleh kebudayaan dan peradaban berupaya perkembangan tekhnologi yang berkembang pesat. Pengetahuan itu sifatnya universal yang artinya menyeleruh dengan semua lapisan masyarakat, kemudian berdasarkan.

$\begin{array}{rcr}\text { Dedi } & \begin{array}{c}\text { Supriadi dalam Jalaluddin } \\ \text { pengetahuan } \\ \text { dapat dicermati }\end{array} \text { dengan }\end{array}$


kreativitas perkembangan atau disebut juga kreativitas keilmuan (scientific creatifity) yang bertujuan untuk mencari dan menemukan kebenaran keilmuan (scientific truth). Kegiatan keilmuan itu sendiri tidak dapat dilepaskan dari kreativitas ilmuwan itu sendiri. Para pakar pengetahuan juga mengetahui akan pengetahuan selalu berkembang dan mengikuti kebutuhan akan zaman dan ilmu pengetahuan memiliki ciriciri yang spesifik mengenai apa (ontologi), bagaimana (estiomologi) dan untuk apa (aksiologi) pengetahuan tersebut disusun.

Pengetahuan itu sendiri bisa didapatkan dengan pengalaman manusia yang beraktifitas sehari-hari, dengan banyak aktifitas maka semakin banyak pula pengalaman serta pengetahuan yang banyak dan melampaui batas yang didapatkan dan dan pengetahuan ini bisa diperoleh dengan perantara indera, kata seorang penganut empirisme.

"John Locke, bapak empirisme Britania, dalam Louis O Kattsouf mengatakan bahwa pada waktu manusia dilahirkan, akalnya merupakan sejenis buku catatan yang kosong (tabula rasa), dan didalam buku catatan itulah dicatat pengalaman-pengalaman inderawi. Menurut Locke, seluruh sisa pengetahuan kita diperoleh dengan jalan menggunakan serta membandingkan ide-ide yang diperoleh dari penginderaan dan refleksi yang pertama-tama dan sederhana tersebut.

Jadi berdasarkan penguraian diatas maka dapat disimpulkan bahwa pengetahuan adalah pikiran manusia yang dalam kesadaran dalam melakukan suatu kegiatan mengamati, menyelidiki, percaya, hasrat dan maksud serta intensitas.

\section{KESELAMATAN}

Zaman modern ini menuntut manusia untuk bekerja keras untuk menghasilkan nominal yang tak berhingga sampai mendapat kepuasaan diri sendiri, kemudian untuk menghasilkan itu manusia berupaya melakukan apapun untuk kepentingan diri sendiri tapi menyampingkan keselamatan dirinya dan lingkungan yang kemudian mengakibatkan kecelakaan bagi manusia itu sendiri dan berakibat fatal bagi diri sendiri dan orang lain.

Makna keselamatan di zaman modern ini bagi khalayak manusia itu tidak penting karena dengan perkembangan zaman, tetapi sebagai manusia yang memiliki pengetahuan sebaiknya harus memahami pentingnya kata keselamatan bagi manusia.

Keselamatan dalam di abad 21 memiliki banyak definisi yang bervariasi dari berbagai para ahli yang berpendapat mengenai arti dari keselamatan tersebut. Abad 21 ini keselamatan sangat penting dalam kehidupan manusia dan manusia harus memahami apa itu keselamatan.

Keselamatan kerja adalah sarana utama untuk pencegahan kecelakaan, cacat dan kematian sebagai akibat kecelakaan kerja. Keselamatan kerja yang baik adalah pintu gerbang bagi keamanan tenaga kerja.

Keselamatan itu juga harus mengutamakan konsep safety management yaitu keselamatan yang harus dimanagement dalam mewujudkan keselamatan yang direncanakan untuk menghindari kecelakaan pada saat melakukan kegiatan kegiatan. Dan Petersen, Frank Bird, dan James Tye dalam Soehatman Keselamatan dan kesehatan kerja harus dikelola dengan menerangkan konsep manajemen modern. Aspek keselamatan dan kesehatan kerja merupakan bagian integral dari sistem manajemen dalam organisasi.

Kehidupan sehari-hari keselamatan bisa melingkupi ruas kegiatan manusia dalam beraktifitas, aktifitas indoor maupun outdoor. Aktifitas outdoor adalah kegiatan yang banyak menggunakan ruang dan lingkungan dan sebanding dengan resiko dan kecelakaan, maka dari itu peran keselamatan dalam kegiatan outdoor sangat penting untuk beraktifitas. Banyak sekali yang beranggapan aktifitas indoor minim akan kecelakaan dan faktanya dilapangan banyak sekali yang terjadi kecelakaan karena melanggar nilai keselamatan itu sendiri. Banyak para ahli yang mengemukakan pendapat keselamatan itu penting dikegiatan indoor maupun outdoor. 
Perkembangan ilmu pengetahuan tekhnologi, konteks keselamatan merupakan modal utama kesejahteraan manusia dalam bekerja secara keseluruhan dan keselamatan harus diterapkan yang baik dan terarah. Keselamatan juga memliki hubungan antara ergonomi dan sudah ada pada zaman Yunani, ergonomi dikenal dalam bahasa Yunani, dari kata ergos dan nomos yang memiliki arti "kerja" dan "aturan atau "kaidah". Secara pengertian bebas sesuai dengan perkembangannya.

Suatu aturan atau kaidah yang ditaati dalam lingkungan pekerjaan. Ditinjau dari kata historis, ergonomi telah menyatu dengan budaya manusia sejak zaman megalitik, dalam proses perancangan dan pembuatan bendabenda seperti alat kerja dan barang buatan sesuai dengan kebutuhan manusia pada zamannya.

Ergonomi memiliki hubungan dengan keselamatan dan mengikuti perkembangan zaman dan ergonomi banyak dikemukakan para ahli yang mendefinisikan arti ergonomi tersebut. Pada era 21 atau globalisasi ergonomi penting dan berkesinambungan denga keselamatan merupakan faktor kelasungan hidup manusia dengan selamat dikehidupan sehari-hari.

"Secara hakiki keselamatan dan kesehatan kerja, merupakan upaya atau pemikiran serta penerapannya yang ditujukan untuk menjamin keutuhan dan kesempurnaan baik jasmaniah maupun rohaniah tenaga kerja khususnya dan manusia pada umumnya, hasil karya dan budaya, untuk meningkatkan kesejahteraan tenaga kerja.

Kamus Besar Bahasa Indonesia dalam Buku F.A Gunawan \& Waluyo Bahaya adalah yang mungkin mendatangkan kecelakaan yang berupa bencana, kesengsaraan, kerugian dan sebagainya. sedangkan bahaya(hazard) ialah sesuatu keadaan yang biasanya berbentuk energi dan mempunyai potensi untuk menyebabkan cedera pada manusia atau kerusakan pada harta benda maupun lingkungan alam.

Bahaya merupakan suatu kecelakaan yang kelak akan mengakibatkan resiko, bahaya itu sangat berkaitan dengan resiko karena resiko itu adalah dampak dari setelah terjadinya bahaya, banyak pendapat yang mengemukakan definisi risiko kemungkinan atau potensi terjadinya sesuatu yang menimbulkan kerugian.

Banyak faktor yang bisa mempengaruhi keselamatan antara lain peralatan yang tidak sesuai prosedur, kelengahan setiap individu, lingkungan yang tidak bersahabat untuk meyesuaikan prinsip keselamatan, akan tetapi untuk melakukan pencegahan sebaiknya harus melakukan tindakan cermat dalam bekerja, pengecekan alat, dan sebagainya untuk mewujudkan keselamatan.

Keselamatan adalah suatu keadaan aman, dalam suatu kondisi yang aman secara fisik, sosial, spiritual, finansial, politis, emosional, pekerjaan, psikologis, ataupun pendidikan dan terhindar dari ancaman terhadap faktor-faktor tersebut. Untuk mencapai hal ini, dapat dilakukan perlindungan terhadap suatu kejadian yang memungkinkan terjadinya kerugian ekonomi atau kesehatan.

Selama Beraktifitas manusia pun tidak luput dari kecelakaan akan dirinya walaupun seorang individu itu telah memenuhi standarisasi akan keselamatan akan tetapi bencana kecelakaan itu tidak bisa diprediksi dengan kemampuan manusia maka dari itu untuk menanggulangi kecelakaan tersebut diperlukan suatu tindakan pertama atau yang disebut P3K (Pertolongan Pertama pada Kecelakaan). P3K adalah Pertolongan Pertama Perawatan pada Kecelakaan yang bertujuan untuk menyelamatkan korban, mengeringankan penderitaan korban serta mencegah bahaya lanjut akibat kecelakan, mempertahankan daya tahan korban sampai lebih baik dan membawa kepada tim medis terdekat.

Berikut Rekomendasi umum untuk Kotak Isi P3K. 
Tabel 1. Isi Kotak P3K

\begin{tabular}{|c|c|c|c|c|}
\hline $\begin{array}{l}\mathrm{N} \\
\mathrm{o}\end{array}$ & Isi & $\begin{array}{c}\text { Kotak } \\
\text { A } \\
(0-25 \\
\text { Pekerja } \\
)\end{array}$ & $\begin{array}{c}\text { Kotak } \\
\text { B (26- } \\
50 \\
\text { Pekerja } \\
\text { ) }\end{array}$ & $\begin{array}{c}\text { Kotak } \\
\text { C }(51- \\
100 \\
\text { Pekerja } \\
\quad)\end{array}$ \\
\hline 1 & $\begin{array}{l}\text { Kasa } \\
\text { Steril } \\
\end{array}$ & 20 & 40 & 40 \\
\hline 2 & $\begin{array}{c}\text { Perban } \\
\text { Lebar } 5 \\
\mathrm{~cm}\end{array}$ & 1 & 2 & 4 \\
\hline 3 & $\begin{array}{c}\text { Perban } \\
\text { Lebar } \\
7,5 \mathrm{~cm}\end{array}$ & 1 & 3 & 6 \\
\hline 4 & $\begin{array}{c}\text { Plester } \\
\text { Lebar } \\
1,25 \\
\mathrm{~cm}\end{array}$ & 1 & 1 & 2 \\
\hline 5 & $\begin{array}{c}\text { Plester } \\
\text { cepat }\end{array}$ & 10 & 15 & 20 \\
\hline 6 & $\begin{array}{l}\text { Kapas } \\
25 \\
\text { gram }\end{array}$ & 1 & 2 & 3 \\
\hline 7 & $\begin{array}{c}\text { Perban } \\
\text { Segitig } \\
\mathrm{a}\end{array}$ & 4 & 4 & 6 \\
\hline 8 & $\begin{array}{c}\text { Guntin } \\
\mathrm{g}\end{array}$ & 1 & 1 & 1 \\
\hline 9 & Peniti & 4 & 4 & 6 \\
\hline 10 & $\begin{array}{l}\text { Sarung } \\
\text { Tangan }\end{array}$ & 2 & 2 & 4 \\
\hline 11 & Masker & 1 & 1 & 2 \\
\hline 12 & $\begin{array}{c}\text { Aquade } \\
\text { s } 100 \\
\text { ml }\end{array}$ & 1 & 2 & 4 \\
\hline 13 & $\begin{array}{c}\text { Povido } \\
\text { n oil } 60 \\
\mathrm{ml}\end{array}$ & 1 & 2 & 2 \\
\hline 14 & $\begin{array}{l}\text { Alkoho } \\
170 \% \\
\end{array}$ & 1 & 1 & 1 \\
\hline 15 & $\begin{array}{c}\text { Buku } \\
\text { Pandua } \\
\text { n P3K }\end{array}$ & 1 & 1 & 1 \\
\hline 16 & $\begin{array}{c}\text { Buku } \\
\text { Catatan }\end{array}$ & 1 & 1 & 1 \\
\hline 17 & $\begin{array}{c}\text { Daftar } \\
\text { Isi } \\
\text { Kotak }\end{array}$ & 1 & 1 & 1 \\
\hline
\end{tabular}

Didunia keselamatan perlu adanya budaya keselamatan unggul yaitu ada tiga unsur adalah kepimpinan keselamatan (Safety leadership), sistem manajemen keselamatan terintegrasi (Integrated safety management system), dan keterlibatan personal atau karyawan (Employee involment).

Jadi berdasarkan uraian diatas maka dapat disimpulkan. Bahwa keselamatan adalah suatu keadaan yang terbebas dari bahaya agar mendapat keselamatan diri, keselamatan psikologis, keselamata fisik, dan keselamatan pengalaman dengan tujuan menunjang kegiatan sehari-hari.

Kenyamanan Diri adalah suatu keadaan seseorang paham dengan pengetahuan keselamatan, untuk memprioritaskan keselamatan dan merupakan perwujudan keselamatan itu suatu kebutuhan menyangkut kenyamanan psikologis, kenyamanan psikologis merupakan keadaan individu (seseorang) yang mempentingkan kondisi emosi dan jiwa untuk bertujuan keselamatan dirinya. Keselamatan pun meliputi keselamatan fisik, kenyamanan fisik adalah keadaan seseorang yang mengutamakan tubuhnya (organ) untuk dilindungi, dan keadaan fisiknya sebagai cerminan keselamatan. Kenyamanan pengalaman adalah seseorang yang telah mengikuti suatu kegiatan yang mengandung nilai kehidupan untuk diterapkan dalam hidupnya yang berdasarkan keselamatan untuk menghindari bahaya maupun kecelakaan untuk mewujudkan kehidupan yang lebih baik.

Definisi pengetahuan keselamatan adalah pikiran terbebas dari keadaan bahaya dengan tujuan kenyamanan diri, kenyamanan fisik, kenyamanan psikologi dan pengalaman untuk menunjang kegiatan manusia atau individu dikehidupan sehari-hari.

\section{PENGUNJUNG}

Pengunjung adalah seseorang yang melakukan kegiatan untuk melakukan aktifitas atau kunjungan kesuatu daerah atau negara dengan tujuan bekerja, berekreasi menjadi wisatawan disuatu tempat yang dikunjungi. 
Menurut WTO membagi wisatawan kedalam tiga bagian yaitu:

a) Pengunjung adalah setiap orang yang berhubungan ke suatu negara lain dimana ia mempunyai tempat kediaman, dengan alasan melakukan pekerjaan yang diberikan oleh negara yang dikunjunginya.

b) Wisatawan adalah setiap orang yang bertempat tinggal di suatu negara tanpa tanpa memandang kewarganegaraannya, berkunjung kesuatu tempat pada negara yang sama untuk waktu lebih dari 24 jam yang tujuan perjalanannya dapat diklasifikasikan sebagai berikut :

1. Memanfaatkan waktu luang untuk rekreasi, liburan, pendidikan, dan

kesehatan

2. Bisnis atau mengunjungi kaum keluarga.

3. Untuk menambahkan pengalaman akan tempat baru.

4. Sebagai refrensi untuk mengajak sanak saudara untuk mengunjungi.

5. Untuk dijadikan momentum mengabadikan diri di tempat yang baru.

\section{ARUNG JERAM}

Arung jeram adalah aktifitas pengarungan bagian alur sungai yang berjeram dengan menggunakan wahana tertentu. Pengertian wahana dalam hal ini adalah sarana atau alat yang terdiri atas perahu karet, kayak, kano dan dayung. Kegiatan arung jeram juga memadukan unsur olahraga, rekreasi, petualangan, dan edukasi. Memang taka da persyaratan khusus untuk mengikuti kegiatan ini, karena semua orang dapat mencobanya mulai dari anak-anak, remaja sampai dewasa, bahkan orang tua yang berumur 60 tahun sekalipun.

A. Peralatan Pengarungan

1. Perahu

Perahu yang terbentuk dari tabung udara yang terbuat dari bahan karet berserat. Di dalam tabung tersebut ada sekat-sekat yang membentuk sel atau ruangan yang terpisah, sehingga jika salah satu sel bocor yang lain tidak akan berpengaruh. Tipe-tipenya antara lain :

\section{Bermesin)}

Landing Craft Rubber (Perahu

Papan kayu dibelakang perahu untuk kedudukan mesin. Cocok untuk pendaratan dilaut atau disungai yang lebar dan tenang. Dapat juga dipakai untuk sungai arus deras, namun papan belakangnya sering tersangkut dibatu.

\section{$>\quad$ River Boat}

Dibuat khusus untuk mengarungi sungai arus deras. Permukaan dasar perahu dibuat sedemekian rupa sehingga bidang sentuh dengan airnya kecil, untuk mengurangi hambatan dari laju perahu pada arus sungai.

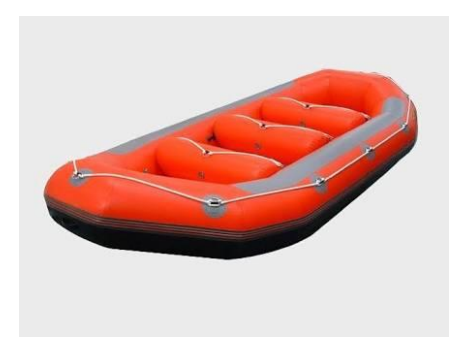

Gambar 1. Perahu

Sumber : Rafting-boat.com

Diakses 1 Desember 2016

\section{Dayung (Paddle)}

Berfungsi untuk menggerakkan, mengarahkan dan untuk mengemudikan perahu. Jenis yang biasa digunakan adalah dayung alumunium dan plastik, karena dayung ini cukup ringan, terapung di air dan lebih kuat dari dayung lainnya seperti dayung kayu dan fiber glass.

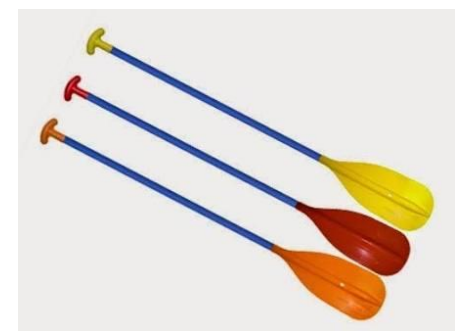

Gambar 2. dayung

Sumber : Pusat perahu karet Indonesia.com Diakses 1 Desember 2016 
3. Pelampung

Pelampung yang baik adalah pelampung padat yang mempunyai bagian khusus untuk melindungi bagian belakang kepala. Selain itu memiliki daya apung sekitar $10-15 \mathrm{Kg}$. Kelamahan pelampung padat yaitu jika dalam keadaan air, dalam jangka waktu tertentu daya apungnya berkurang karena penyerapan air pada bahan busanya.

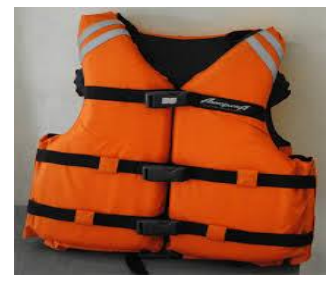

Gambar 3. Pelampung

Sumber : Pelampung-arung-jeram.com

Diakses 1 Desember 2016

\section{Helm}

Umum digunakan dari bahan plastik. Pada bagianbelakang helm terdapat ukuran kepala dan bisa disesuaikan besar kecilnya sesuai kepala anggota.

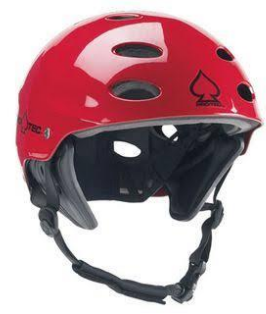

Gambar 4. Helm

Sumber : Peralatan-rafting.com

Diakses 1 Desember 2016

\section{Dry Bag}

Merupakan kantong atau tas kedap air. Digunakan untuk menyimpan barangbarang yang tidak boleh terkena air seperti P3K, repair kit, dll. Usahakan tidak membawa barang-barang yang berlebihan agar beban perahu tidak terlalu besar.

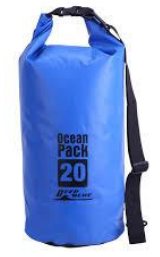

Gambar 5. Dry bag

Sumber : Ocean Park.com

Diakses 1 Desember 2016

\section{Sepatu}

Sepatu karet atau sepatu kets yang ringan dengan sel luar bergerigi. Dapat juga menggunakan sepatu tenis.

B. Aba- aba Dalam Pengarungan.

1. Dayung maju : seluruh anggota mendayung kedepan

2. Dayung mundur: seluruh anggota mendayung kebelakang.

3. Kanan maju : arah perahu dibelokkan kekiri, yang duduk disebelah kanan mendayung maju, yang sebelah kiri stop.

4. Kiri maju : arah perahu dibelokkan kekanan, yang duduk disebelah kanan stop mendayung, yang sebelah kiri mendayung maju.

5. Draw kanan : perahu digeser kekanan dengan arah perahu tidak berubah.

6. Draw kiri : perahu digeser kekiri dengan arah perahu tidak berubah.

7. Stop : seluruh anggota berhenti mendayung, hanya dua orang dibelakang yang menjadi mudi supaya arah perahu tetap lurus.

\section{Posisi Duduk Di Perahu}

1. Cowboys Style

Posisi duduk ditabung perahu dan posisi kaki direnggangkan untuk menjepit tabung yang berfungsi menjaga keseimbangan tubuh diperahu. Kelemahan diposisi ini adalah kaki yang ada diluar perahu bisa berakibat fatal karena sebagian anggota tubuh kita 
berada diluar yang bisa berbentur dengan hambatan atau apapun tebing disekitar sungai tersebut. Maka posisi ini hanya digunakan ketika arus tenang.

\section{Ladies Style}

Posisi dimana kedua kaki berada didalam perahu dan biasanya ujung kaki diselipkan pada tempat yang telah disediakan. Posisi ini sangat nyaman karena jauh dari benturan tebing atau hambatan lain.

\section{SUNGAI CISADANE}

Cisadane adalah salah satu sungai besar di Tatar Pasundan, Pulau Jawa, yang bermuara ke Laut Jawa. Pada masa lalu, sungai ini juga disebut dengan nama $\mathrm{Ci}$ Gede (Chegujde, Cheguide) setidaknya pada bagian sekitar muaranya.

Hulu sungai ini berada di lereng Gunung Pangrango dengan beberapa anak sungai yang berawal di Gunung Salak, melintas di sisi barat Kabupaten Bogor, terus kearah Kabupaten Tangerang dan bermuara di sekitar Tanjung Burung. Dengan panjang keseluruhan sekitar $126 \mathrm{~km}$, sungai ini pada bagian hilirnya cukup lebar dan dapat dilayari oleh kapal kecil.

Pada abad ke-16 Tangerang (disebut oleh Tom Pires sebagai Tamgaram) yang berada ditepi sungai ini, telah menjadi salah satu pelabuhan yang penting namun kemudian kalah oleh perkembangan Banten dan Batavia.

Sungai Cisadane yang berada dikota Bogor merupakan aliran sungai terbesar di Jawa Barat sampai menuju Tangerang, Banten. Sungai Cisadane ini sering dimanfaatkan penduduk sekitar untuk kegiatan sehari-hari seperti mencuci pakaian, mencuci perkakas dan alat masak yang dimiliki ibu rumah tangga. Sungai Cisadane ini bisa dijadikan tempat bermain anak-anak untuk kegiatan bermain ataupun mandi disungai.

Sungai Cisadane ini merupakan tempat objek wisata yang bisa dijadikan sebagai tempat aktifitas arung jeram, pada setiap hari sabtu dan minggu maupun hari libur nasional, tempat ini ramai dikunjungi para pengunjung yang ingin melakukan aktifitas arung jeram. Para pengunjung biasanya berasal dari Jakarta, Tangerang, Depok dan Bekasi mengunjungi tempat arung jeram disungai Cisadane ini.
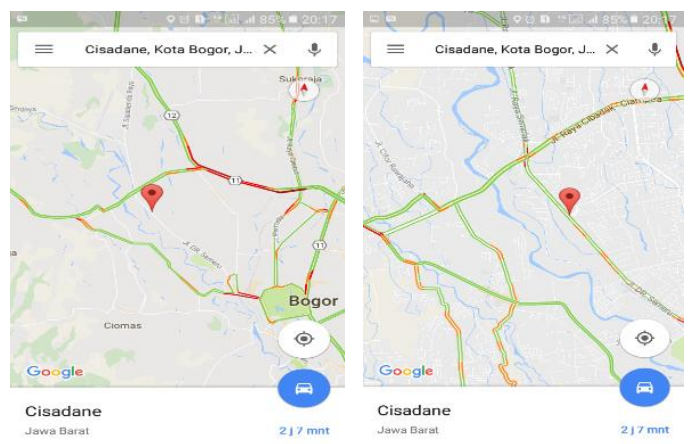

Gambar 6. Peta Sungai Cisadane

Sumber : Google Maps

Diakses 1 Desember 2016

\section{Kerangka Berpikir}

Arung jeram merupakan olahraga ekstrem yang banyak disukai masyarakat dengan menikmati serta menjalankannya banyak kepuasaan dan pengalaman yang didapat, kegiatan arung jeram ini bisa dilakukan secara berkelompok, dengan mengajak teman teman dan kerabat, arung jeram ini juga bisa dijadikan sebagai acara selfi ria dan sebagainya. Pada kenyatannya arung jeram ini mengakibatkan banyak korban yang berjatuhan disebabkan banyak beberapa faktor, yaitu tentang pengetahuannya akan keselamatan diri sendiri dan orang lain.

Alur kerangka berpikir ini akan dimulai dari aliran sungai Cisadane. Aliran sungai cisadane merupakan tempat yang sering diadakan kegiatan arung jeram, tempat ini merupakan tempat favorit bagi para penghobby arung jeram karena memiliki medan yang sangat menantang serta memiliki keseruan yang tidak ada batasnya, tidak menutupi medan yang menantang bisa mengakibatkan faktor tentang keselamatan menjadi diabaikan. 


\section{INSTRUMEN PENELITIAN}

Instrumen yang digunakan untuk mengumpulkan data dalam penelitian ini adalah dengan cara pengisian pertanyaan yang telah disiapkan oleh peneliti tentang pengetahuan keselamatan bagi pengunjung.

Tabel 2. Kisi Kisi Pengetahuan Keselamatan untuk Pengunjung Arung Jeram Cisadane

Bogor Jawa Barat.

\begin{tabular}{|c|c|c|c|c|c|}
\hline $\begin{array}{l}\mathrm{N} \\
\mathrm{O}\end{array}$ & $\begin{array}{c}\mathrm{V} \\
\mathrm{ar} \\
\mathrm{ia} \\
\mathrm{b} \\
\mathrm{el}\end{array}$ & $\begin{array}{l}\text { Indika } \\
\text { tor }\end{array}$ & Sub Indikator & $\begin{array}{c}\text { Pe } \\
\text { rta } \\
\text { ny } \\
\text { aa } \\
\text { n } \\
\mathrm{Pe} \\
\text { ng } \\
\text { eta } \\
\text { hu } \\
\text { an }\end{array}$ & $\begin{array}{l}\mathrm{Ju} \\
\mathrm{ml} \\
\text { ah } \\
\text { So } \\
\text { al }\end{array}$ \\
\hline \multirow{7}{*}{1} & \multirow{7}{*}{ 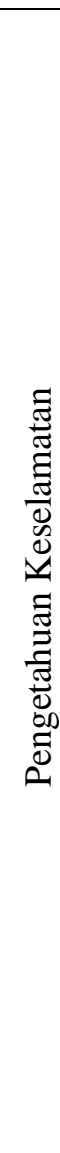 } & \multirow{3}{*}{$\begin{array}{c}\text { Kenya } \\
\text { manan } \\
\text { Diri }\end{array}$} & $\begin{array}{l}\text { Pengetahuan } \\
\text { Keselamatan }\end{array}$ & 2 & 2 \\
\hline & & & $\begin{array}{l}\text { Keselamatan } \\
\text { Prioritas } \\
\text { Utama }\end{array}$ & 2 & 2 \\
\hline & & & $\begin{array}{l}\text { Keselamatan } \\
\text { Suatu } \\
\text { Kebutuhan }\end{array}$ & 2 & 2 \\
\hline & & \multirow{2}{*}{$\begin{array}{c}\text { Kenya } \\
\text { manan } \\
\text { Psikol } \\
\text { ogi }\end{array}$} & $\begin{array}{l}\text { Kenyamanan } \\
\text { Psikologi } \\
\text { Merupakan } \\
\text { Faktor } \\
\text { Keselamatan }\end{array}$ & 1 & 1 \\
\hline & & & $\begin{array}{l}\text { Kesehatan } \\
\text { Psikologi } \\
\text { Berhubungan } \\
\text { Dengan } \\
\text { Keselamatan }\end{array}$ & 1 & 1 \\
\hline & & \multirow[b]{2}{*}{$\begin{array}{l}\text { Kenya } \\
\text { manan } \\
\text { Fisik }\end{array}$} & $\begin{array}{l}\text { Keselamatan } \\
\text { Fisik itu } \\
\text { Faktor Penting }\end{array}$ & 2 & 2 \\
\hline & & & $\begin{array}{l}\text { Tubuh Harus } \\
\text { Di lindungi } \\
\text { Untuk } \\
\text { Menunjang } \\
\text { Keselamatan }\end{array}$ & 2 & 2 \\
\hline
\end{tabular}

\begin{tabular}{|c|c|c|c|c|} 
& $\mid$\begin{tabular}{l|l|l|} 
Keamanan \\
Diri Cerminan \\
Keselamatan
\end{tabular} & 2 & 2 \\
\hline & $\begin{array}{l}\text { Pengalaman } \\
\text { Cerminan Diri } \\
\text { Keselamatan }\end{array}$ & 2 & 2 \\
\cline { 2 - 4 } $\begin{array}{l}\text { Kenya } \\
\text { manan } \\
\text { Penga } \\
\text { laman }\end{array}$ & $\begin{array}{l}\text { Faktor Bahaya } \\
\text { Sebagai } \\
\text { Acuan Untuk } \\
\text { Keselamatan }\end{array}$ & 2 & 2 \\
\cline { 2 - 4 } & $\begin{array}{l}\text { Nilai } \\
\text { Kehidupan } \\
\text { Merupakan } \\
\text { Nilai } \\
\text { Keselamatan }\end{array}$ & 2 & 2 \\
\hline
\end{tabular}

\section{HASIL PENELITIAN}

Pada penelitian ini terdapat 20 pertanyaan dalam bentuk tanggapan "YA" atau "TIDAK". Pertanyaan-pertanyaan ini dijadikan dalam bentuk angket yang diberikan kepada para pengunjung arung jeram cisadane Bogor, Jawa Barat. Pembahasan ini dimulai dengan mengklasifikasikan hasil angket yang telah disebarkan kepada 60 responden $(n=60)$, data tersebut dimasukan tabel-tabel dan diagram pie.

- $\quad$ Tabel 3 Rentangan nilai dalam kategori rendah, sedang dan tinggi sebagai berikut :

\begin{tabular}{|c|c|}
\hline $\begin{array}{l}\text { Kategori tingkat Pengetahuan } \\
\text { Keselamatan }\end{array}$ & $\begin{array}{c}\text { Rentangan } \\
\text { Nilai }\end{array}$ \\
\hline Rendah & $0-20$ \\
\hline Sedang & $21-40$ \\
\hline Tinggi & $41-60$ \\
\hline
\end{tabular}

Rumus untuk menghitung presentasi jumlah responden berdasarkan kategori, sebagai berikut:

$\mathrm{P}=\frac{\Sigma \mathrm{X}}{n} \times 100 \%$.

Keterangan :

$\mathrm{n}=$ Jumlah Responden

$\sum \mathrm{x}=$ Jumlah Skor

$\mathrm{P}=$ Angka Presentasi 


\section{ANALISIS DATA}

Langkah-langkah mencari presentase setiap dimensi pertanyaan berdasarkan jumlah jawaban responden, kemudian menginterpretasikan hasil jawaban setiap dimensi.

Tabel 4 Interpretasi Hasil Analisis Data dari setiap Dimensi.

\begin{tabular}{|c|c|c|}
\hline No & Pertanyaan & Interpretasi \\
\hline 1. & $\begin{array}{l}\text { Kenyamanan } \\
\text { Diri }\end{array}$ & $\begin{array}{l}\text { Pengunjung } \\
\text { merasa aman } \\
\text { ketika dirinya } \\
\text { selamat dan } \\
\text { tentram dalam } \\
\text { pengarungan } \\
\text { disungai } \\
\text { Cisadane Bogor, } \\
\text { Jawa Barat. }\end{array}$ \\
\hline 2. & $\begin{array}{l}\text { Kenyamanan } \\
\text { Fisik }\end{array}$ & $\begin{array}{l}\text { Pengunjung } \\
\text { merasa aman } \\
\text { ketika anggota } \\
\text { fisiknya utuh dan } \\
\text { tidak ada yang } \\
\text { hilang ketika } \\
\text { pengarungan } \\
\text { jeram di sungai } \\
\text { Cisadane, Bogor, } \\
\text { Jawa Barat. }\end{array}$ \\
\hline 3. & $\begin{array}{l}\text { Kenyamanan } \\
\text { Psikologi }\end{array}$ & $\begin{array}{l}\text { Pengunjung } \\
\text { merasa aman } \\
\text { dengan kondisi } \\
\text { mental nya pada } \\
\text { saat melakukan } \\
\text { pengarungan } \\
\text { jeram di sungai } \\
\text { Cisadane, Bogor, } \\
\text { Jawa Barat. }\end{array}$ \\
\hline 4. & $\begin{array}{l}\text { Kenyamanan } \\
\text { Pengalaman }\end{array}$ & $\begin{array}{l}\text { Pengunjung } \\
\text { mendapat } \\
\text { pengalaman yang } \\
\text { menarik, } \\
\text { menegangkan dan } \\
\text { seru ketika } \\
\text { melakukan } \\
\text { pengarungan } \\
\text { jeram di sungai } \\
\text { Cisadane, Bogor, } \\
\text { Jawa Barat. }\end{array}$ \\
\hline
\end{tabular}

Tiap aspek memiliki nilai maksimal yang sama. Untuk dimensi keselamatan diri nilainya 60 , keselamatan fisik nilainya 60 , keselamatan psikologi nilainya 60 dan keselamatan pengalaman nilainya 60 . Sehingga frekuensi kategori untuk tiap aspek hasilnya sebagai berikut:

Tabel 5. Frekuensi Kategori Tingkat Pengetahuan Keselamatan Pengunjung Arung Jeram di Sungai Cisadane, Bogor, Jawa Barat.

\begin{tabular}{|c|l|c|c|c|}
\hline \multirow{2}{*}{$\begin{array}{c}\mathrm{N} \\
\mathrm{o}\end{array}$} & \multicolumn{1}{|c|}{ Aspek } & $\begin{array}{c}\text { Ting } \\
\mathrm{gi}\end{array}$ & $\begin{array}{c}\text { Sedan } \\
\mathrm{g}\end{array}$ & $\begin{array}{c}\text { Renda } \\
\mathrm{h}\end{array}$ \\
\hline 1. & $\begin{array}{l}\text { Kenyaman } \\
\text { an Diri }\end{array}$ & $50 \%$ & $50 \%$ & $0 \%$ \\
\hline 2. & $\begin{array}{l}\text { Kenyaman } \\
\text { an Fisik }\end{array}$ & $40 \%$ & $60 \%$ & $0 \%$ \\
\hline 3. & $\begin{array}{l}\text { Kenyaman } \\
\text { an } \\
\text { Psikologi }\end{array}$ & $30 \%$ & $70 \%$ & $0 \%$ \\
\hline 4. & $\begin{array}{l}\text { Kenyaman } \\
\text { an } \\
\text { Pengalama } \\
\mathrm{n}\end{array}$ & $60 \%$ & $40 \%$ & $0 \%$ \\
\hline
\end{tabular}

1. Aspek Kenyamanan Diri.

Berdasarkan hasil penelitian pada aspek kenyamanan diri dibagi menjadi 3 kategori yaitu : tinggi, sedang dan rendah dengan tabel data sebagai berikut

Tabel 6. Kategori aspek kenyamanan diri

\begin{tabular}{|c|c|c|}
\hline No & Skor & Kategori \\
\hline 1. & $41-60$ & Tinggi \\
\hline 2. & $21-40$ & Sedang \\
\hline 3. & $0-20$ & Rendah \\
\hline
\end{tabular}


Frekuensi aspek kenyamanan diri pada saat pengunjung berada di tempat arung jeram disungai Cisadane, Bogor, Jawa Barat.

Tabel 7. Frekuensi aspek kenyamanan diri

\begin{tabular}{|c|c|c|c|}
\hline No & Kategori & Jumlah & Presentase \\
\hline 1. & Tinggi & 30 orang & $50 \%$ \\
\hline 2. & Sedang & 30 orang & $50 \%$ \\
\hline 3. & Rendah & 0 orang & $0 \%$ \\
\hline
\end{tabular}

Dari tabel diatas, terlihat bahwa pengunjung arung jeram sungai Cisadane, Bogor, Jawa Barat, dengan kategori tinggi $50 \%$ (30 orang), kategori sedang 50\% (30 orang) dan kategori rendah $0 \%$ (0 orang).

Presentase pengunjung tersebut dapat dilihat pada grafik diagram pie dibawah ini :

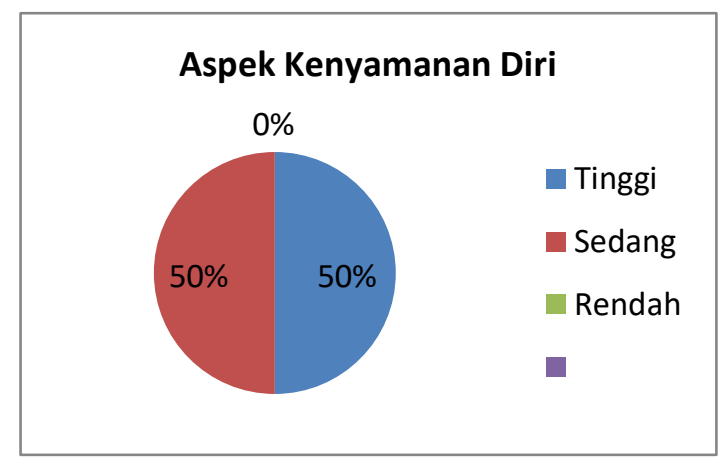

\section{Gambar 7. Diagram Pie aspek Kenyamanan}

\section{Aspek Kenyamanan Fisik}

Berdasarkan hasil penelitian pada aspek kenyamanan fisik dibagi menjadi 3 kategori yaitu : tinggi, sedang dan rendah dengan tabel sebagai berikut :
Tabel 8. Kategori aspek kenyamanan fisik.

\begin{tabular}{|c|c|c|}
\hline No & Skor & Kategori \\
\hline 1. & $41-60$ & Tinggi \\
\hline 2. & $21-40$ & Sedang \\
\hline 3. & $0-20$ & Rendah \\
\hline
\end{tabular}

Frekuensi aspek kenyamanan fisik pada saat pengunjung berada di tempat arung jeram disungai Cisadane, Bogor, Jawa Barat.

Tabel 9 Frekuensi aspek kenyamanan fisik.

\begin{tabular}{|c|c|c|c|}
\hline No & Kategori & Jumlah & Presentase \\
\hline 1. & Tinggi & 20 orang & $40 \%$ \\
\hline 2. & Sedang & 40 orang & $60 \%$ \\
\hline 3. & Rendah & 0 orang & $0 \%$ \\
\hline
\end{tabular}

Dari tabel diatas, terlihat bahwa pengunjung arung jeram sungai Cisadane, Bogor, Jawa Barat, dengan kategori tinggi $40 \%$ (20 orang), kategori sedang 60\% (40 orang) dan kategori rendah $0 \%$ (0 orang).

Presentase pengunjung tersebut dapat dilihat pada grafik diagram pie dibawah ini :

\section{Aspek Kenyamanan Fisik}

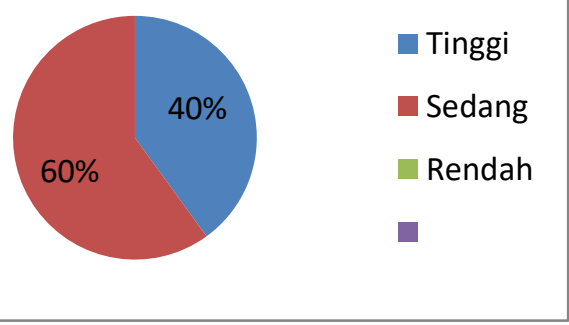

Gambar 8. diagram pie aspek kenyamanan fisik 
3. Aspek Kenyamanan Psikologi

Berdasarkan hasil penelitian pada aspek kenyamanan psikologi dibagi menjadi 3 kategori yaitu : tinggi, sedang dan rendah dengan tabel sebagai berikut

Tabel 10. Kategori aspek kenyamanan psikologi

\begin{tabular}{|c|c|c|}
\hline No & Skor & Kategori \\
\hline 1. & $41-60$ & Tinggi \\
\hline 2. & $21-40$ & Sedang \\
\hline 3. & $0-20$ & Rendah \\
\hline
\end{tabular}

Frekuensi aspek kenyamanan psikologi pada saat pengunjung berada ditempat arung jeram sungai Cisadane, Bogor, Jawa Barat.

Tabel 11. Frekuensi aspek kenyamanan psikologis.

\begin{tabular}{|c|c|c|c|}
\hline No & Kategori & Jumlah & Presentase \\
\hline 1. & Tinggi & 15 orang & $30 \%$ \\
\hline 2. & Sedang & 45 orang & $70 \%$ \\
\hline 3. & Rendah & 0 orang & $0 \%$ \\
\hline
\end{tabular}

Dari tabel diatas, terlihat bahwa pengunjung arung jeram sungai Cisadane, Bogor, Jawa Barat, dengan kategori tinggi 30\% (15 orang), kategori sedang $70 \%$ (45 orang) dan kategori rendah $0 \%$ (0 orang).

Presentase pengunjung tersebut dapat dilihat pada grafik diagram pie dibawah ini :

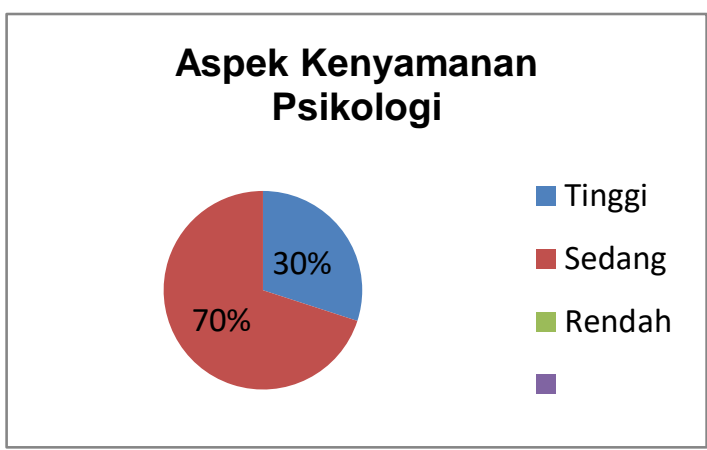

Gambar 9. diagram pie aspek kenyamanan psikologi

4. Aspek Kenyamanan Pengalaman

Berdasarkan hasil penelitian pada aspek kenyamanan pengalaman dibagi menjadi 3 kategori yaitu : tinggi, sedang dan rendah dengan tabel sebagai berikut :

Tabel 12. Kategori aspek kenyamanan pengalaman.

\begin{tabular}{|c|c|c|}
\hline No & Skor & Kategori \\
\hline 1. & $41-60$ & Tinggi \\
\hline 2. & $21-40$ & Sedang \\
\hline 3. & $0-20$ & Rendah \\
\hline
\end{tabular}

Tabel 13 Frekuensi aspek kenyamanan pengalaman

\begin{tabular}{|c|c|c|c|}
\hline No & Kategori & Jumlah & Presentase \\
\hline 1. & Tinggi & 30 orang & $50 \%$ \\
\hline 2. & Sedang & 30 orang & $50 \%$ \\
\hline 3. & Rendah & 0 orang & $0 \%$ \\
\hline
\end{tabular}

Dari tabel diatas, terlihat bahwa pengunjung arung jeram sungai Cisadane, Bogor, Jawa Barat, dengan kategori tinggi $50 \%$ (30 orang), kategori sedang 50\% (30 orang) dan kategori rendah $0 \%$ (0 orang). 
Presentase pengunjung tersebut dapat dilihat pada grafik diagram pie dibawah ini:

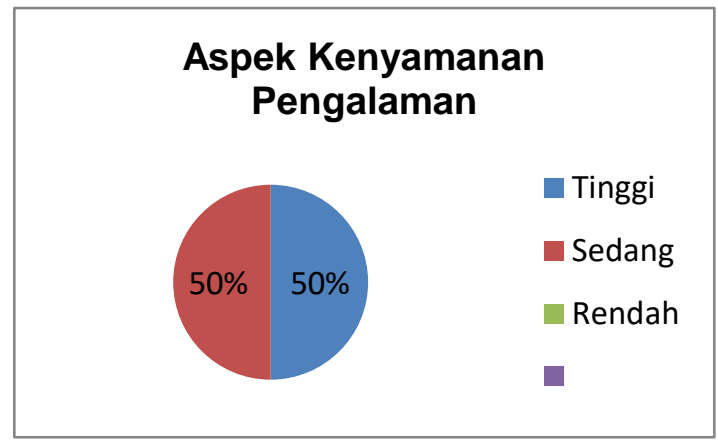

Gambar 10. diagram pie aspek kenyamanan psikologi

\section{PEMBAHASAN KARATERISTIK MASYARAKAT SUNGAI CISADANE}

Masyarakat di bantaran sungai cisadane sangat ramah terhadap wisatawan yang berkunjung untuk merasakan wahana arung jeram di kampungnya, masyarakat sangat antusias ketika ada pengunjung sehingga mereka berlomba-lomba memberikan pelayanan optimal kepada pengunjung arung jeram berupa makanan dan minuman yang segar, bahkan masyarakat dibantaran sungai cisadane sering mengajak pengunjung untuk memancing bersama-sama dengan tujuan silahturahmi, selain itu masyarakatnya penuh dengan keharmonisan sesama tetangga dan para pengelola vendor arung jeram, pengunjung pun sering berfoto dengan masyarakat dan mereka sangat senang karena bisa mempromosikan desa nya ke mancanegara dan internasional dengan bertujuan meningkatkan tempat wisata arung jeram di desanya.

Berkunjung di wisata sungai cisadane, Bogor Jawa Barat juga dapat menambahkan gairah semangat kerja dan juga bisa menanamkan nilai kerja sama serta kekompakan dalam kelompok di dalam kegiatan arung jeram. Kegiatan arung jeram dapat menambah wawasan dan pengetahuan. Berbagai macam aktualisasi diri serta mengeksplorasi alam bisa didapatkan dengan kegiatan arung jeram yang seru dan mengasyikan.

Sungai Cisadane, Bogor, Jawa Barat terdapat berbagai macam-macam spot atau tempat yang sungguh memanjakkan mata ketika melakukan pengarungan jeram, contohnya pemandangan sawah-sawah milik warga kondisi sungai yang bersih, pemandangan gunung salak yang indah dan hijau serta keramahan warga sekitar ketika menyapa para pengunjung.

Sungai Cisadane mendukung sekali dalam kegiatan arung jeram, sebab sungai cisadane memiliki jeram yang bisa membuat hati seseorang merasa senang dan berdebar ketika berada di atas perahu dan melewati jeram dengan teman kelompoknya. Sungai cisadane juga memiliki sejarah yang panjang akan ceritanya dan seru untuk dieksplorasi dengan teman, kerabat dan keluarga.

\section{KESIMPULAN}

Berdasarkan analisis data penelitian tentang tingkat pengetahuan keselamatan pada pengunjung arung di Sungai Cisadane, Bogor, Jawa Barat menunjukkan data dari 4 dimensi yaitu

Kenyamanan diri menyatakan $50 \%$ pengunjung memiliki pengetahuan keselamatan tinggi (30 orang), $50 \%$ sedang (30 orang), $0 \%$ rendah ( 0 orang).

Kenyamanan fisik menyatakan $40 \%$ kategori tinggi (20 orang), $60 \%$ kategori sedang (40 orang) $0 \%$ rendah (0 orang) rendah.

Kenyamanan Psikologi menyatakan $30 \%$ (15 orang) kategori tinggi, kategori sedang $70 \%$ (45 orang), $0 \%$ rendah (0 orang).

Kenyamanan Pengalaman menyatakan $50 \%$ kategori tinggi (30 orang), 50\% kategori sedang (30 orang), $0 \%$ rendah (0 orang).

Berdasarkan hasil analisis data menunjukkan bahwa pengunjung yang berkunjung di wisata sungai Cisadane, Bogor Jawa Barat memiliki tingkat pengetahuan yang sedang dan menjadi alasan mereka melakukan kegiatan arung jeram.

Faktor keselamatan diri, fisik, psikologi dan pengalaman adalah faktor pendukung 
yang mendorong pengunjung melakukan arung jeram, baik itu secara individu maupun kelompok. Selain melepaskan kepenatan dari aktifitas sehari-hari, kegiatan arung jeram juga dapat menambahkan pengalaman, mendapatkan pengetahuan arung jeram dan juga bisa berolahraga di alam terbuka.

\section{SARAN}

Berdasarkan pembahasan hasil penelitian, dan kesimpulan yang telah dipaparkan, maka disampaikan saran-saran sebagai berikut:

1. Bagi User atau Pengelola arung jeram agar lebih lagi meningkatkan peralatan safety untuk para pengunjung secara maksimal, dalam keselamatan, kebutuhan akan para pengunjung, agar segala bentuk kecelakaan diarung jeram tidak terjadi lagi, sehingga pengunjung bisa melakukan kegiatan arung jeram dengan rasa aman dan nyaman.

2. Untuk para pengunjung wisata sungai Cisadane, Bogor Jawa Barat lebih memperhatikan lagi tentang tingkat pengetahuan keselamatan, dengan cara membaca refrensi tentang pengetahuan keselamatan dan pengetahuan arung jeram.

3. Dapat memberikan acuan, pengetahuan dan refrensi tempat wisata sungai cisadane, Bogor Jaw Barat khususnya para pembaca dan mahasiswa Fakultas Ilmu Keolahragaan Universitas Negeri Jakarta.

\section{DAFTAR PUSTAKA}

Ahmad Tafsir, Filsafat Ilmu Mengurai Ontologi, Epistemologi dan Aksiologi Pengetahuan (Bandung:PT Remaja Rosdakarya,2012)

Aripin Banasuru, Filsafat dan Filsafat Ilmu (Bandung: Alfabeta,2013)

A. Susanto, Filsafat Ilmu(Jakarta:PT Bumi Aksara,2014)
Buntarto, Panduan Praktis Keselamatan \& Kesehatan Kerja Industri (Yogyakarta: Pustaka Baru Press,2015)

F.A. Gunawan \& Waluyo, Risk Based Behavioral Safety (Jakarta:PT Gramedia Pustaka Utama,2015)

Jalaluddin, Filsafat Ilmu Pengetahuan, Filsafat, Ilmu Pengetahuan dan peradaban (Jakarta: PT Grafindo,2015)

John Ridley, Kesehatan dan Keselamatan Kerja (Jakarta: Erlangga,2006)

Jujun S. Suriasumantri, Filsafat Ilmu Pengantar Populer (Jakarta: Pustaka Sinar Harapan,2003)

KMPA EKA CITRA, Diktat Materi Dasar Ilmu Kepencitaalaman Pendidikan Dan Latihan Dasar (Jakarta: KMPA EKA CITRA,2014)

Louis O. Kattsouf Pengantar Filsafat (Yogyakarta: Tiara Wicana Yogya,2004)

Moh.Nazir, Metode Penelitian (Bogor:Ghalia Indonesia,2011)

Nono Sudarsono dan Setria, Olahraga Alam (Jakarta: PT Perca,2008)

Rudi Suardi, Sistem Manajemen Keselamatan \& Kesehatan Kerja (Jakarta: PPM,2005)

Soehatman Ramli, Sistem Manajemen Keselamatan \& Kesehatan Kerja OHSAS 18001 (Jakarta: Dian Rakyat,2014)

Suma'mur, Keselamatan Kerja \& Pe.... zahan Kecelakaan (Jakarta: PT Toko Gunung Agung,2014)

Surajiyo, Filsafat Ilmu dan Perkembangan di Indonesia (Jakarta:PT Bumi Aksara,2013)

V.Wiratma Sujarweni, Metodologi Penelitian (Yogyakarta: Pustaka Baru Press,2014)

Wowo Sunaryo Kusnawan, Ergonomi dan K3 Kesehatan Keselamatan Kerja (Bandung: PT Remaja Rosdakarya,2014) 